Int. J. Plant Sci. 165(2):281-288. 2004.

(c) 2004 by The University of Chicago. All rights reserved.

$1058-5893 / 2004 / 16502-0006 \$ 15.00$

\title{
CAN A GENETIC CORRELATION WITH SEED MASS CONSTRAIN ADAPTIVE EVOLUTION OF SEEDLING DESICCATION TOLERANCE IN WILD BARLEY?
}

\author{
Koen J. F. Verhoeven, ${ }^{1, *}$ Arjen Biere, ${ }^{*}$ Eviatar Nevo, $†$ and Jos M. M. van Damme* \\ *Department of Plant Population Biology, Netherlands Institute of Ecology, Center for Terrestrial Ecology, \\ Heteren, The Netherlands; and Institute of Evolution, University of Haifa, Haifa, Israel
}

\begin{abstract}
Very young seedlings of wild barley Hordeum spontaneum have the ability to survive extended periods of severe drought. This desiccation tolerance is considered an adaptation to the rain-limited and unpredictable habitats that the species occupies. Genetic variation has been observed for this trait, but the limited evidence to date does not consistently show that genotypes from more xeric populations have better desiccation tolerance. As large seed endosperm volume may buffer the desiccating seedling from drought stress, we explored the hypothesis that tolerance to temporary but severe drought is affected by seed mass. We crossed a big-seeded with a small-seeded $H$. spontaneum genotype and measured seed mass and seedling survival rates after 6-d desiccation in $140 \mathrm{~F}_{4}$ progeny families. A positive correlation was observed between family mean scores of the two traits. At the genetic level, this indicated that at least some genes underlying variation in the two traits overlapped (or show close chromosomal linkage), which is inevitable if seed mass causally affects desiccation tolerance. Quantitative Trait Loci (QTL) analysis, which can identify chromosome regions responsible for trait variation by exploring associations between trait expression and genetic markers dispersed over the genome, did not confirm this hypothesis of shared genetic control. Despite the lack of QTL evidence, the observed genetic association between seed mass and desiccation tolerance indicates that the two traits are not fully independent, implying that selection targeting one trait will cause a correlated response in the other. We discuss this finding in the context of adaptive differentiation of $H$. spontaneum populations, which is thought to involve selection of increasingly smaller seeds along a gradient of decreasing predictability and amount of annual precipitation.
\end{abstract}

Keywords: Hordeum spontaneum, adaptation, drought, QTL analysis, correlated selection.

\section{Introduction}

In the highly seasonal growing environments of Mediterranean and steppic climates, the scarcity and unpredictability of precipitation events pose a main challenge to successful germination and seedling establishment (Evenari et al. 1971; Gutterman 1993; Blondel and Aronson 1999). In annual plants, several strategies have been described to cope with this problem. Seed dormancy prevents germination after incidental rain during the otherwise dry summer months (Evenari 1965; Gutterman 1993). A combination of delayed germination in a fraction of the seeds and high persistence in the seed bank can distribute germination over different rainfall events or years (Cohen 1966), thereby spreading the risk of mortality if early-season rain is followed by a long period of drought. In addition, germinated seeds or seedlings of some species can survive prolonged desiccation and develop new roots and leaves on rewetting (Evenari et al. 1971; Friedman et al. 1981). The "point of no return" (Evenari

\footnotetext{
${ }^{1}$ Author for correspondence; current address: Computational Genomics, Department of Agronomy, Purdue University, 915 West State Street, West Lafayette, Indiana 47907-2054, U.S.A.; telephone 765-496-3362; fax 765-496-2926; e-mail kverhoeven@purdue.edu.
}

Manuscript received August 2003; revised manuscript received December 2003. et al. 1971), after which a seedling can no longer recover from full desiccation, depends on the duration and rate of dehydration (Friedman et al. 1981) and may be reached only at a rather advanced stage of germination. For instance, barley seedlings with root lengths exceeding $4 \mathrm{~cm}$ and emerged coleoptiles have been shown to survive severe desiccation (Gutterman and Gozlan 1998).

In wild barley Hordeum spontaneum, seedling desiccation tolerance varies between genotypes from different habitats (Gutterman and Gozlan 1998; Zhang et al. 2002; Chen et al. 2004). Hordeum spontaneum, the recognized progenitor of cultivated barley (Zohary 1969), is a diploid, self-fertilizing annual grass species with generally low levels of outcrossing (Brown et al. 1978) that occurs in Mediterranean and steppic vegetation types in the Near East Fertile Crescent and penetrates into favorable desert microhabitats (Harlan and Zohary 1966; Zohary 1969; Nevo et al. 1979). Phenotypic and genetic variation among Israeli $H$. spontaneum populations are correlated to ecological and climatic factors (Nevo et al. 1984; Snow and Brody 1984; Nevo et al. 1986), and local adaptation at the regional scale is thought to be driven mainly by a north-to-south gradient of decreasing amount and predictability of precipitation (Nevo 1992; Volis et al. 2002b). Although desiccation tolerance conceivably confers a greater fitness advantage in low-rainfall and low-predictability areas, empirical evidence to date does not consistently show that 
genotypes from xeric populations show higher desiccation tolerance than genotypes from mesic populations or even commercial barley cultivars (Gutterman and Gozlan 1998; Zhang et al. 2002; but see Chen et al. 2004).

In this study, we test the hypothesis that seedling desiccation tolerance is affected by seed mass. In germinating barley grains, water stored in the endosperm retracts toward the embryo during desiccation, thereby reducing both the rate and the degree of dehydration stress in the developing embryo (Allen et al. 2000). This indicates that a larger endosperm volume may confer better protection of the embryo, or of basal meristematic tissue, against temporary drought. In $H$. spontaneum, populations from xeric environments typically produce smaller seeds than populations from mesic environments (Nevo et al. 1984; Snow and Brody 1984; Volis et al. 2002c), presumably because a trade-off between total seed number and mean seed mass has different adaptive outcomes in habitats that differ in predictability. It is thought that more intense seedling competition in mesic habitats has favored genotypes that produce big (but fewer) seeds, whereas increased benefits of germination risk-spreading in xeric habitats favored production of many (but smaller) seeds (Volis et al. 2002a, 2002b). If seed mass affects desiccation tolerance, then selection targeting the former trait will cause a correlated response in the latter. As a result, and depending on the strength of the association, variation in desiccation tolerance among populations might not show the expected correlation with water availability if selection on seed mass is intense.

The hypothesis that desiccation tolerance is causally affected by seed mass translates at the genetic level into the hypothesis that there is at least partial overlap in the genetic control of the two traits; there may be genes that only affect desiccation tolerance, but the genes that affect seed mass must also show an effect on desiccation tolerance. We used a QTL (quantitative trait loci) approach to study the genetic relationship between the two traits (Remington and Purugganan 2003) and analyzed the $\mathrm{F}_{4}$ progeny of a $H$. spontaneum cross between a big-seeded genotype from a Mediterranean coastal population and a small-seeded genotype from an inland steppic population. In QTL analyses, associations are explored in a segregating population between trait variation and allelic variation at genetic markers dispersed over the entire genome, thereby identifying chromosome regions on a linkage map that are responsible for trait variation (Lander and Botstein 1989). Crossing and subsequent selfing of the progeny break up the specific combinations of alleles that were present in the parental genotypes (Falconer and Mackay 1996). Because of recombination and segregation, many hybrid genotypes are created that possess unique combinations of the two parental genomes. Unlinked alleles are therefore not expected to remain consistently associated across the progeny population. The hypothesis of shared genetic control, in contrast, predicts that seed mass and desiccation tolerance remain associated despite recombination and segregation events. In the $\mathrm{F}_{4}$ progeny of our cross, this should be reflected by (1) a significant correlation between line mean scores of the two traits across the recombinant $\mathrm{F}_{4}$ genotypes; and (2) colocation on the linkage map of at least some QTLs for the two traits.

\section{Material and Methods}

\section{Plants}

We analyzed the recombinant progeny of a cross between a plant from a coastal Hordeum spontaneum population near Ashqelon (AQ) and a plant from an inland population near Mehola (ME), Israel (accessions 28-77 and 22-28 from the Gene Bank of the Institute of Evolution, Haifa University, Israel; an accession represents the selfed progeny from a single seed collected in the field). The ME population is characterized by fast-growing, early flowering plants that produce many small seeds (Nevo et al. 1984; Elberse et al. 2003; Verhoeven et al. 2004a, 2004b), typical of the steppic and desert H. spontaneum ecotypes in Israel (Nevo et al. 1984; Snow and Brody 1984; Volis et al. 2002a). Compared to ME, plants from AQ produce bigger but fewer seeds and flower later and grow taller, which is typical of Mediterranean H. spontaneum populations in Israel (Nevo et al. 1984; Snow and Brody 1984; Volis et al. 2002a). Annual precipitation at both sites is low (AQ: $424 \mathrm{~mm}$; ME: $270 \mathrm{~mm}$; Nevo et al. 1984); lower annual precipitation is associated with increasing unpredictability of precipitation events (Jaffe 1988; Volis et al. 2002b). Since the AQ and ME genotypes typically differ in mean seed mass, recombinant progeny of the $\mathrm{AQ} \times \mathrm{ME}$ cross are expected to show large genetic variation for this trait, providing a suitable tool for assessing whether and how seed mass affects seedling desiccation tolerance.

From the $\mathrm{AQ} \times \mathrm{ME}$ cross, $140 \quad \mathrm{~F}_{2}$ individuals were selffertilized to yield $140 \mathrm{~F}_{3}$ families (described in $\mathrm{H}$. Poorter et al., unpublished manuscript). Ten plants per $\mathrm{F}_{3}$ family were bulk propagated under greenhouse conditions by selffertilization, resulting in 140 seed batches that each represent an $\mathrm{F}_{2}$-derived $\mathrm{F}_{4}$ family.

\section{Desiccation Experiment}

Dispersal units were deawned, leaving the lateral (sterile) spikelets and glumes attached to the caryopsis; hereafter, we will refer to these deawned dispersal units as seeds. After storage at $40^{\circ} \mathrm{C}$ for $2 \mathrm{mo}$, seeds were weighed in batches of 16 , yielding a mean seed mass score for each of the $140 \mathrm{~F}_{4}$ families and the two parental accessions. Seeds were surface sterilized by submergence in $0.4 \%(\mathrm{w} / \mathrm{v})$ sodium hypochlorite for $5 \mathrm{~min}$ to minimize fungal infection during the experiment, rinsed with demineralized water, and placed in $8.5-\mathrm{cm}$ petri dishes on filter paper moistened with $3.5 \mathrm{~mL}$ demineralized water (16 seeds per petri dish, four dishes per genotype, 568 petri dishes in total). To synchronize germination, petri dishes were kept at $4^{\circ} \mathrm{C}$ in darkness for $7 \mathrm{~d}$ and were transferred to a growth cabinet $\left(20^{\circ} \mathrm{C}, 16 \mathrm{~L}: 8 \mathrm{D}\right.$, PAR 50-70 $\mu \mathrm{mol} \mathrm{m}^{-2} \mathrm{~s}^{-1}$ ) for $4 \mathrm{~d}$. Subsequently, germinated seeds were transferred individually to marked positions in new petri dishes on dry filter paper, and coleoptile length was determined for each seedling. We only included seedlings with coleoptile lengths exceeding $5 \mathrm{~mm}$ (on average 11.5 individuals per dish) and discarded less-developed seedlings that had germinated late or grown slowly, in order to reduce variation caused by (physiological) age differences between individuals. Seedlings were dried for $6 \mathrm{~d}$ in open dishes at constant relative humidity of $30 \%-40 \%\left(20^{\circ} \mathrm{C}\right.$, in darkness $)$, rewetted by 
adding $4 \mathrm{~mL}$ demineralized water to each petri dish, and placed in a growth cabinet $\left(20^{\circ} \mathrm{C}, 16 \mathrm{~L}: 8 \mathrm{D}\right.$, PAR $\left.50-70 \mu \mathrm{mol} \mathrm{m} \mathrm{m}^{-2} \mathrm{~s}^{-1}\right)$. After $7 \mathrm{~d}$, the fate of each individual was determined; survivors were recognized by a turgid, green basis of the coleoptile that indicated regrowth. The experiment was carried out in four consecutive replicate blocks, with each block containing one petri dish per genotype.

\section{Data Analysis}

Genotypic effects on seed mass were determined via univariate ANOVA (Generalized Linear Models procedure in SAS Institute 1997; four 16-seed mass scores for each family). Survival probability of individual seedlings after desiccation as affected by genotype and block effects was analyzed using Generalized Linear Models (type III analysis with logit link function and binomial error distribution; GENMOD procedure in SAS). As survival probability is strongly dependent on the seedling's stage of development and may reach an optimal value several days after the onset of germination (Gutterman and Gozlan 1998), coleoptile length (at the start of the desiccation treatment) and its quadratic value were included in the analysis as covariates. To account for possible dependence of responses within petri dishes, we modeled correlations within the block $\times$ genotype interaction, i.e., within individual petri dishes, using the Generalized Estimation Equation approach in the GENMOD procedure (SAS Institute 1997). Family mean values for desiccation survival probability were calculated as adjusted means in this model.

In order to compare the magnitude of genotypic effects on seed mass and on desiccation survival probability, we also analyzed survival probability at the petri dish level (i.e., proportion of survivors per dish). Using dishes as replicates $(n=4)$, we calculated within-family and between-family variance components for both traits via partitioning of the sum of squares, and within-family and between-family covariance components via partitioning of the sum of products. This also permitted us to estimate the genetic correlation $\left(r_{\mathrm{a}}\right)$ between seed mass and desiccation survival probability by dividing the between-family covariance component by the square root of the product of between-family variance components of the two traits (Falconer and Mackay 1996).

The relationship between family mean values for seed mass and desiccation survival was analyzed using model 1 (ordinary least squares) regression. Although both variables are estimated with error and neither is under experimental control, model 2 regression was considered inappropriate, because the error variance in the estimates of the dependent variable (survival probability) proved much larger than in the estimates of the explanatory variable (seed mass; see "Results" section) (Legendre and Legendre 1998).

\section{QTL Analysis}

$\mathrm{F}_{2}$ progeny from the $\mathrm{AQ} \times \mathrm{ME}$ cross used in this study were characterized for 196 AFLP and six SSR markers, and a genetic linkage map was constructed as described in $\mathrm{H}$. Poorter et al. (unpublished manuscript). The map was estimated to cover $55 \%$ of the entire genome, and a core map was derived for QTL analysis containing 96 of the most informative and equally spaced markers. Using $\mathrm{F}_{3}$ trait scores, this mapping population has been used previously to map QTLs for seed mass, growth rate-related traits, plasticity in growth traits, and fitness traits (Verhoeven et al. 2004b; Elberse et al., in press; H. Poorter et al., unpublished manuscript). In this study, we searched for QTLs affecting seedling desiccation tolerance and seed mass using the MapQTL mapping software (PRI, Wageningen, Netherlands). We used mean trait values of each $\mathrm{F}_{4}$ family as estimates for their respective $\mathrm{F}_{2}$ grandparents and analyzed the data set as an $\mathrm{F}_{2}$ design. Interval mapping analyses were carried out, followed by composite interval mapping (MQM) with markers near previously detected likelihood of odds (LOD) peaks $(>2.0)$ included in the analysis as cofactors. The MQM procedure was repeated with gradual addition of cofactors until the LOD profiles stabilized, and the final LOD scores were determined using restricted MQM. To control the type I error rate caused by multiple tests during the genome scan, we used permutation tests to set a LOD significance threshold for QTL detection (van Ooijen and Maliepaard 1996). These tests indicated a 5\% mapwise error rate at LOD 3.3 and a 10\% mapwise error rate at LOD 2.9.

\section{Results}

The AQ and ME parents of the cross differed strongly in seed mass. Seeds from the AQ parent were more than twice as heavy as seeds from the ME parent (fig. $1 A$; accession effect in univariate ANOVA: $\left.F_{1,6}=1002, P<0.001\right)$. In the recombinant $\mathrm{F}_{4}$ progeny, the among-genotype effect on seed mass remained highly significant (family effect in univariate ANOVA: $\left.F_{139,420}=13.8, P<0.001\right)$. Of the total variance in seed mass scores, $76 \%$ was partitioned among families. Survival probability after desiccation differed strongly between the parental accessions (fig. $1 B$; table 1 ). More than $80 \%$ of the seeds from the AQ parent survived the desiccation stress, whereas less than $5 \%$ of the seeds from the ME parent survived. There was also significant variation for desiccation tolerance between the recombinant $\mathrm{F}_{4}$ families (table 1 ). The among-family variance component in observed survival proportions per dish was $18 \%$ ( $25 \%$ after correction for variation introduced by among-block variation); this indicates that the proportion of the phenotypic variance that can be explained by genetic differences is much smaller for desiccation tolerance than for seed mass. For neither trait did we observe transgressive segregation; all recombinant $\mathrm{F}_{4}$ families showed mean trait values falling between the two parental scores (fig. 1).

The big-seeded AQ parent showed better survival after desiccation than the small-seeded ME parent, and this positive association between seed mass and desiccation tolerance was maintained in the $\mathrm{F}_{4}$ progeny (fig. 2). Although highly significant, scatter around the regression line was considerable $\left(r^{2}=0.08\right)$, and the regression slope was rather modest compared with the differences in parental scores (see fig. 2). The correlation of line means $(r=0.28, P<0.001)$ provides an estimate of the genetic correlation between the two traits. A slightly higher estimate of $r_{\mathrm{a}}=0.36$ was obtained from analysis of the between-family covariance and variance components for the traits.

Two QTLs for seed mass were detected around or below the $5 \%$ mapwise error rate (fig. 3 ), together explaining $22.9 \%$ 

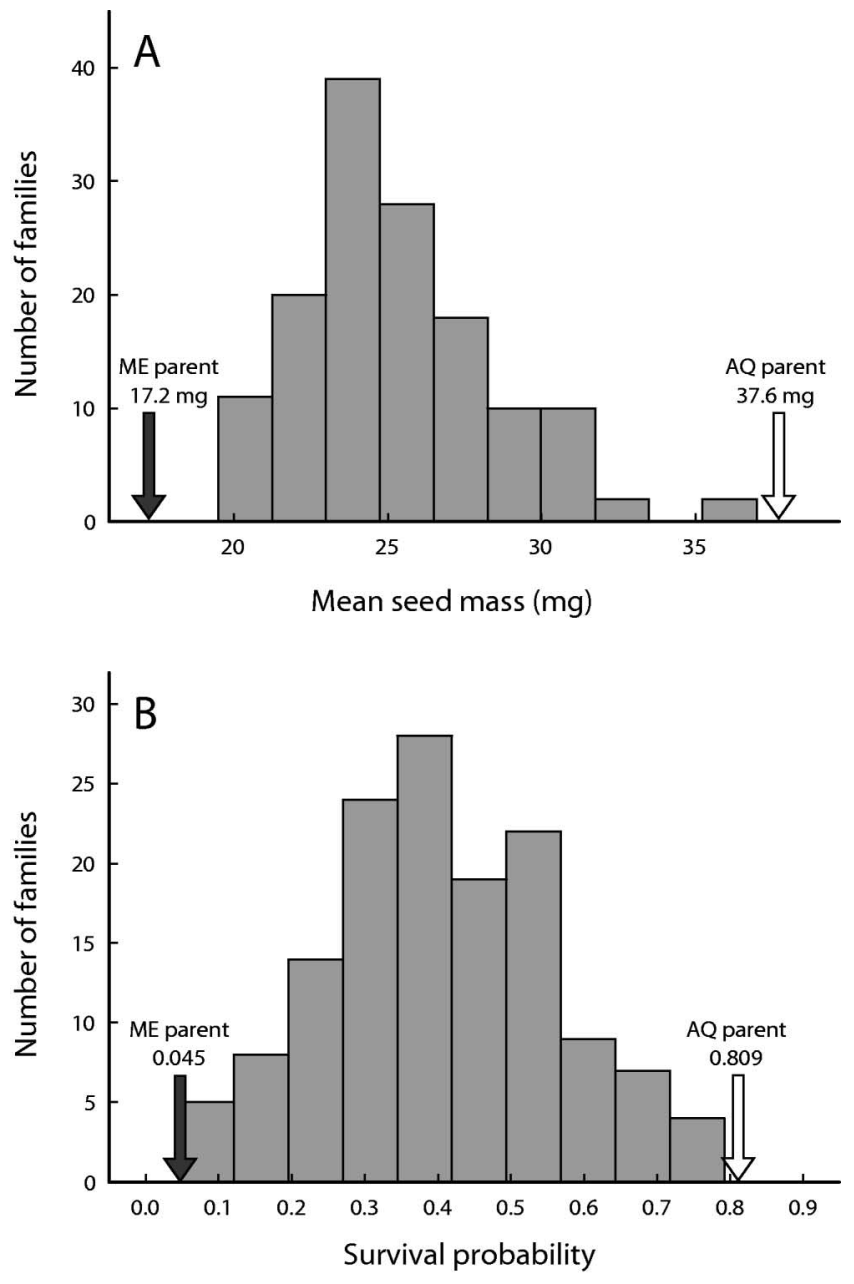

Fig. 1 Histograms showing mean seed mass $(A)$ and survival probability after desiccation $(B)$ for the $140 \mathrm{~F}_{4}$ families from the $\mathrm{AQ} \times \mathrm{ME}$ cross. Arrows indicate accession mean scores for the two parents.

of the variation in family mean scores for mean seed mass (QTL 1: chromosome 4, peak position $14.0 \mathrm{cM}$, LOD 3.21, additive effect $5.6 \%$, explaining $9.6 \%$ of variation in family mean scores for seed mass; QTL 2: linkage group $\mathrm{U}^{\mathrm{a}}$, peak position $0.0 \mathrm{cM}$, LOD 4.23 , additive effect $6.4 \%$, explaining $13.3 \%$ of variation in family mean scores for seed mass). The AQ alleles increased seed mass values at both QTLs. No significant QTLs were found for survival probability after desiccation. LOD scores reached maximum values on linkage groups $3^{\mathrm{a}}, 6$, and $\mathrm{U}^{\mathrm{a}}$ (LOD 2.16, 1.82, and 1.80 respectively). One of these LOD peaks (on $U^{\mathrm{a}}$ ) colocated with a QTL for seed mass, with allelic effects in the same direction. The chromosome region that affected seed mass on linkage group 4 showed no convincing effect on desiccation tolerance.

\section{Discussion}

\section{Phenotypic Evidence}

Our study showed high survival rates of Hordeum spontaneum seedlings that were subjected to 6-d desiccation stress at a rather advanced stage of germination (Gutterman and Gozlan 1998; Zhang et al. 2002; Chen et al. 2004) for the big-seeded AQ genotype but not for the small-seeded ME genotype. A genetic basis of variation in seed mass and desiccation tolerance was indicated by significant genotypic effects for these traits, both among the parental genotypes and among the $\mathrm{F}_{4}$ progeny families. Note that our interpretation of significant among-family variation as reflecting genetic differences assumes that environmental causes of seed trait variation prior to the experiment were negligible. Per family, $\mathrm{F}_{4}$ seeds for the experiment were obtained from $10 \mathrm{~F}_{3}$ plants that were bulk propagated in one large pot. Pots were not replicated, and although the controlled greenhouse conditions provided a rather uniform growing environment for all plants, it is therefore possible that environmental gradients during propagation affected among-family variation in $F_{4}$ seed traits due to environmental differences in maternal $\left(\mathrm{F}_{3}\right)$ effects. However, evidence for true genetic differences between families comes from detection of significant QTLs for seed mass; in QTL analysis environmental causes of amongfamily variation are not expected to lead to significant results, since this variation will not be consistently associated with a specific allele across all families.

The observation that family mean scores of the two traits remained associated in the $\mathrm{F}_{4}$ progeny, despite recombination and segregation, indicates that the inheritance of seed mass and desiccation tolerance is not fully independent: at least some genes controlling the two traits are either closely linked on the chromosomes, or they are, indeed, the same genes. Our crossing design $(\mathrm{AQ} \times \mathrm{ME}$ and three subsequent generations of selfing) cannot distinguish between these two options, because quite large segments of chromosomes may remain associated, but this result is certainly consistent with the hypothesis that seed mass affects seedling desiccation tolerance. The apparent weakening of the association between seed mass and desiccation tolerance from the parental generation to the recombinant $\mathrm{F}_{4}$ families (fig. 2) is consistent with partial, and not complete, overlap in genes controlling the

Table 1

Survival Probability after Desiccation of the AQ and ME Parental Accessions and the Recombinant $F_{4}$ Progeny Families as Affected by Coleoptile Length (Linear and Quadratic), Block, and Genotype

\begin{tabular}{lrrr}
\hline & df & \multicolumn{1}{c}{$\chi^{2}$} & \multicolumn{1}{c}{$P$} \\
\hline Parents: & & & \\
$\quad$ Length & 1 & 2.57 & 0.109 \\
Length $^{2}$ & 1 & 2.01 & 0.156 \\
Block & 3 & 3.70 & 0.296 \\
Accession & 1 & 7.85 & 0.005 \\
F $_{\text {p progeny: }}$ & & & \\
Length & 1 & 2.10 & 0.147 \\
Length & 1 & 5.74 & 0.017 \\
Block & 3 & 85.59 & $<0.001$ \\
Family & 139 & 200.65 & 0.001 \\
\hline
\end{tabular}

Note. Score statistics from Generalized Linear Models (General Estimation Equation approach). Deviance values indicated a good fit of the overall models (parents: $D=62.9, \mathrm{df}=81$, corresponding $\chi^{2} \mathrm{~ns} ; \mathrm{F}_{4}$ progeny: $D=7612, \mathrm{df}=6139$, corresponding $\chi^{2} \mathrm{~ns}$ ). 


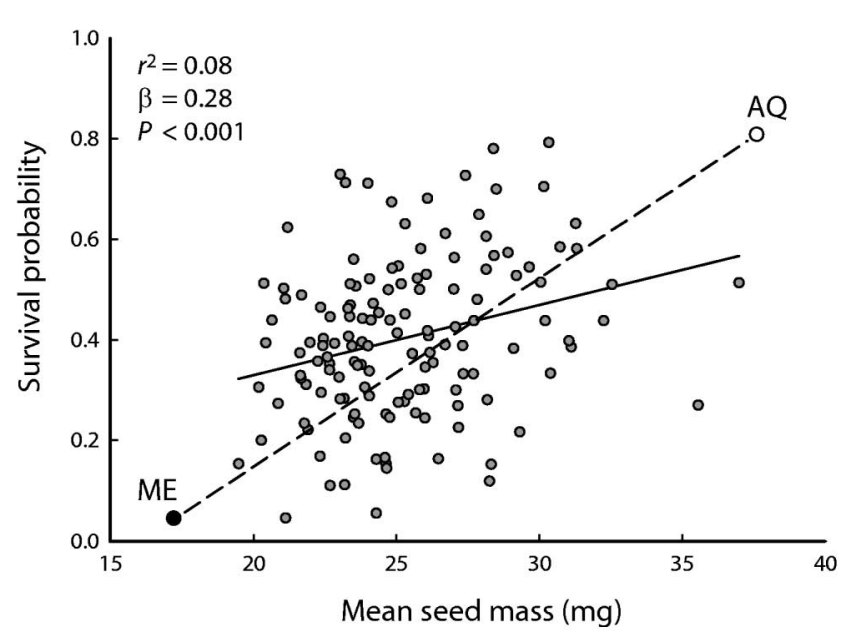

Fig. 2 Relation between seed mass and desiccation tolerance expressed as survival probability after the desiccation treatment in the $\mathrm{F}_{4}$ progeny of the $\mathrm{AQ} \times \mathrm{ME}$ cross. Regression analysis based on family mean values $(n=140)$. The two large circles indicate the two parents (not included in the regression analysis), connected by a dashed line for comparison with the regression slope in the $\mathrm{F}_{4}$ progeny.

two traits. If there is segregation not only at loci that control both traits but also at independent loci that control just one of the traits, then extreme genotypes for one trait (i.e., genotypes possessing all trait-enhancing or all trait-reducing alleles at the polymorphic loci controlling this trait) will generally not be extreme for the other trait as well. This is exactly what we observed; the slope of the regression line of survival probability on mean seed mass in the recombinant $\mathrm{F}_{4}$ progeny was less steep than the slope connecting the parents (fig. 2), which possessed extreme genotypes for both traits, as indicated by the lack of transgressive segregation (fig. 1). Our phenotypic analysis therefore suggests that some chromosome regions affect both seed mass and desiccation tolerance and that other regions may affect only seed mass or only desiccation tolerance.

\section{QTL Evidence}

As expected from the analysis of the parental phenotypes, the AQ alleles significantly increased seed mass scores at the two QTLs detected for this trait. In the $F_{3}$ progeny of the same AQ $\times$ ME mapping population, several seed mass QTLs were detected that we did not pick up in this study (Verhoeven et al. 2004b; Elberse et al., in press; H. Poorter et al., unpublished manuscript; typically showing beneficial effects of AQ alleles). Some of these previously detected QTLs colocated with LOD peaks in our analysis that did not reach the significance threshold (fig. 3). Poor overlap in seed mass QTLs between studies can be partly caused by differences in experimental conditions for maternal plants and by the use of different measures for seed mass between studies (e.g., mass of entire dispersal units in some studies compared with cleaned kernels in others). But even for truly identical traits, QTLs of small effect are often not consistently detected over replicate experiments because of sampling effects and limited statistical power (Beavis 1994). The combined results of the studies using the $\mathrm{AQ} \times \mathrm{ME}$ mapping population strongly indi- cate that seed mass variation is controlled by many genes of modest effect, which is similar to the genetic control of seed mass in Arabidopsis thaliana (Alonso-Blanco et al. 1999), with mass-increasing alleles at nearly all polymorphic loci brought together in the AQ genotype.

We did not detect QTLs for desiccation survival probability, despite pronounced and highly significant variation for this trait between the parents and also among the $\mathrm{F}_{4}$ progeny families. It seems unlikely that this among-family effect is caused by other factors than nuclear genetic variation, such as environmental or maternal effects, because environmental conditions during propagation and in the randomized experiment were well controlled and because all families in the mapping population shared the same maternal ancestry. We therefore believe that QTLs for this trait must be segregating in the mapping population. Failure to detect QTLs in our study can be caused by inadequate statistical power. Notably, survival-probability measurements showed a much larger error variance than did seed mass measurements. Environmental effects typically have lower impact on mean seed mass than on other fitness-related traits in $H$. spontaneum (Volis et al. 2002c). Also, QTLs are conceivably missed because of the incomplete genome coverage of the chromosome map used (H. Poorter et al., unpublished manuscript).

Given the absence of QTLs detected for desiccation tolerance, the QTL results cannot support the hypothesis that seed mass causally affects desiccation tolerance. The absence of an effect on desiccation tolerance of the QTLs that were detected for seed mass (linkage groups 4 and $\mathrm{U}^{\mathrm{a}}$ ) would even argue against this hypothesis. However, as the seed mass QTLs showed effects of modest strength (each QTL explaining $<15 \%$ of observed variation in family mean scores), it is unclear whether the absence of significant effects on desiccation tolerance reflects true absence or inadequate statistical power. Notably, one seed mass QTL on linkage group $\mathrm{U}^{\mathrm{a}}$ colocated with one of the three highest (but nonsignificant) LOD peaks for desiccation tolerance.

\section{Ecological Implications}

Our phenotypic analysis revealed a genetic correlation between seed mass and tolerance to short but severe desiccation that is based on close linkage or shared genes, but our QTL analysis could not confirm this at the genetic level. Because the observed correlation between the two traits did not suggest full overlap in their genetic control, the traits will be partly independent in their responses to selection. However, the genetic association indicates that the traits cannot evolve completely independent of each other: selection targeting one trait will cause a correlated response in the other (Arnold 1992). The generality of the positive association between seed mass and desiccation tolerance can only be established by additional tests. Clearly, QTLs for desiccation tolerance that we did not detect in our experiment may segregate in natural H. spontaneum populations, and such QTLs may or may not be associated with seed mass. For instance, expression of desiccation tolerance is highly dependent on seedling age (Gutterman and Gozlan 1998), and genes that cause variation in desiccation tolerance only at an earlier stage of germination than tested in our experiment will have remained 

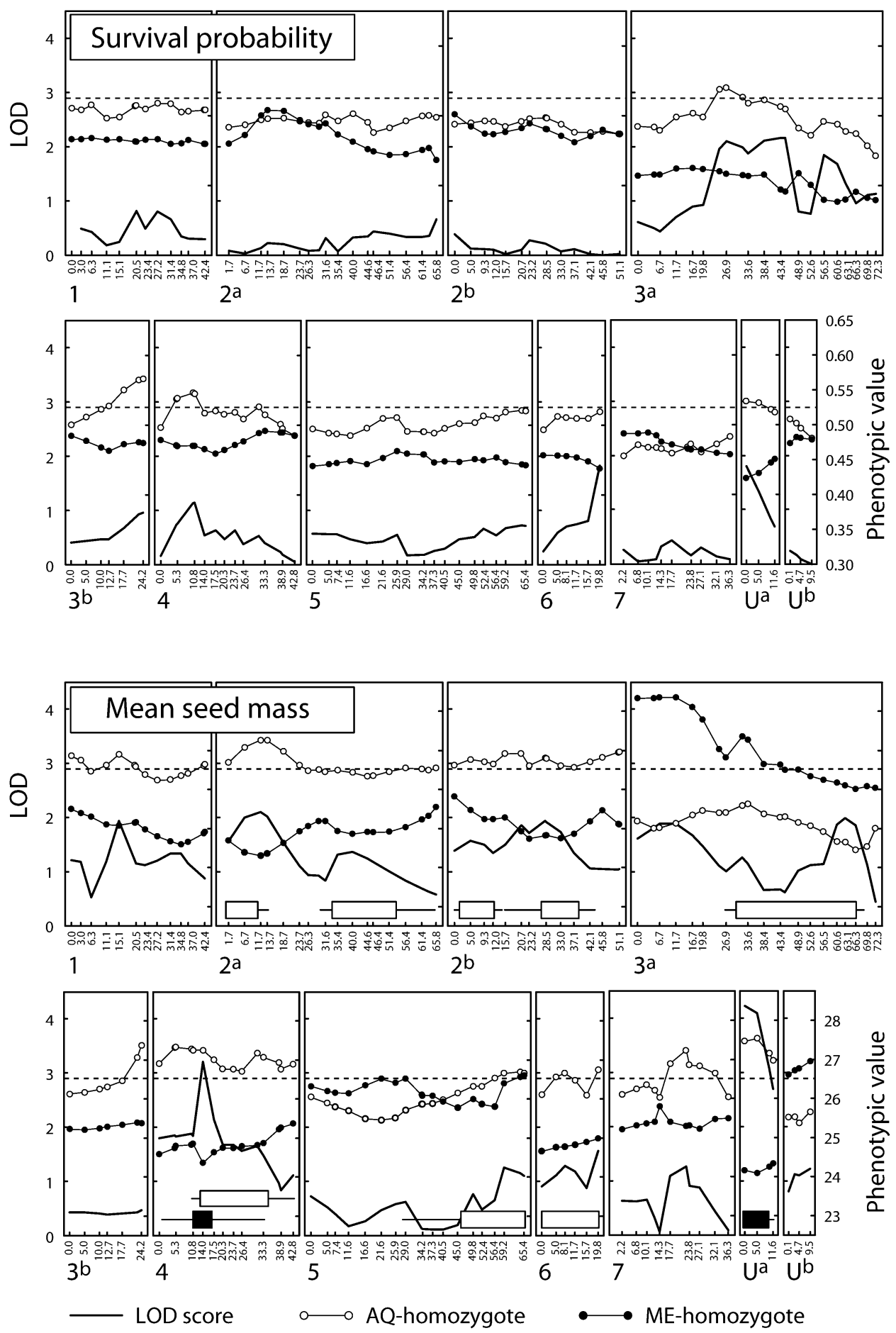

Fig. 3 Chromosomal locations of loci for survival probability after desiccation (top panels) and seed mass (bottom panels). At each position on the linkage map, the 140 families are grouped according to their genotype at that position (AQ homozygote, ME homozygote, or heterozygote), and locus-specific phenotypic values are estimated for each genotype from the observed data (right Y-axis). The LOD test statistic (left Y-axis) indicates the probability that an allelic substitution affects the phenotypic value. Likelihood of odds (LOD) scores above a significance threshold of 2.9 (dashed line) indicate the presence of a Qualitative Trait Loci (QTL) at an adjusted $\alpha$ level of 0.10. Each panel represents one linkage group of the molecular marker map (H. Poorter et al., unpublished manuscript), with marker positions indicated along the $X$-axis. Numbers refer to the seven chromosomes. Two small linkage groups were unassigned $\left(\mathrm{U}^{\mathrm{a}, \mathrm{b}}\right)$. QTLs detected in this study are highlighted as horizontal filled bars, with boxes and whiskers indicating 1 LOD and 2 LOD support intervals, respectively, that correspond roughly to $90 \%$ and $95 \%$ confidence intervals for LOD peak location (van Ooijen 1992). Open bars indicate QTL positions for seed mass that were detected previously using the same AQ $\times$ ME mapping population (see text). 
unnoticed. Also, the AQ and ME parents of our cross may not have been polymorphic for part of the desiccation tolerance genes, which precludes their detection in QTL analysis. However, if the positive association between seed mass and desiccation tolerance that we detected in our study does reflect a general phenomenon, then indirect selection of desiccation tolerance via selection targeting seed mass may be nontrivial in natural populations, since seed mass is considered an important adaptive trait (Harper et al. 1970; Silvertown 1989). Selection pressures favoring big seeds in dry environments would reinforce desiccation tolerance, while selection pressures favoring small seeds would counteract desiccation tolerance. Fitness benefits of big seeds via a positive effect on seedling establishment and competitive ability are well documented (Stanton 1984; Giles 1990; Houssard and Escarré 1991; Volis et al. 2002a). Big seeds are thought to be particularly advantageous in arid environments because their larger seedling size allows deeper penetration of drying soil (Baker 1972; Schimpf 1977; Wulff 1986; Lloret et al. 1999; Schütz et al. 2002). Our study of desiccation tolerance indicates an additional advantage of big seeds in arid environments. However, negative correlations between seed mass and other ecologically relevant traits such as dispersal ability, persistence in the soil bank, and seedling relative growth rate (as suggested in interspecific studies; Marañón and Grubb 1993; Thompson et al. 1993; Westoby et al. 1996), and between seed mass and the total number of seeds that a plant produces (the offspring size vs. number trade-off; Smith and Fretwell 1974), may override the positive fitness consequences of big seeds. The seed size-number trade-off plays a particularly important role in ecotypic differentiation of $H$. spontaneum; selection is thought to have favored production of more, but necessarily smaller, seeds in more xeric environments because this can aid in germination-risk spreading (Volis et al. 2002a, 2002b). The fitness advantage of producing many seeds may outweigh the drought-tolerance advantage of big seeds, causing a constraint in adaptive evolution of desiccation tolerance to the extent that the two traits cannot vary independently of each other.

\section{Acknowledgments}

We would like to thank Ester van Hoek for technical assistance and Piet Stam and Peter van Tienderen for their suggestions on various aspects of the study. Song Weining and Guoxiong Chen gave valuable comments on the manuscript. This work was financially supported by the Earth and Life Sciences Research Council of the Netherlands Organization for Scientific Research (project 805-33-244P). This is publication 3336 for NIOO-KNAW, Netherlands Institute of Ecology.

\section{Literature Cited}

Allen PS, ET Thorne, JS Gardner, DB White 2000 Is the barley endosperm a water reservoir for the embryo when germinating seeds are dried? Int J Plant Sci 161:195-201.

Alonso-Blanco C, H Blankestijn-de Vries, CJ Hanhart, M Koornneef 1999 Natural allelic variation at seed size loci in relation to other life history traits of Arabidopsis thaliana. Proc Natl Acad Sci USA 96:4710-4717.

Arnold SJ 1992 Constraints on phenotypic evolution. Am Nat 140(suppl):S85-S107.

Baker HG 1972 Seed weight in relation to environmental conditions in California. Ecology 53:997-1010.

Beavis WD 1994 The power and deceit of QTL experiments: lessons from comparative QTL studies. Pages 250-266 in DB Wilkinson, ed. 49th Annual Corn and Sorghum Research Conference. American Seed Trade Association, Chicago.

Blondel J, J Aronson 1999 Biology and wildlife of the Mediterranean region. Oxford University Press, Oxford.

Brown AHD, D Zohary, E Nevo 1978 Outcrossing rates and heterozygosity in natural populations of Hordeum spontaneum Koch in Israel. Heredity 41:49-62.

Chen G, T Krugman, T Fahima, F Zhang, E Nevo 2004 Differential patterns of germination and desiccation tolerance of mesic and xeric wild barley (Hordeum spontaneum) in Israel. J Arid Environ 56: 95-105.

Cohen D 1966 Optimizing reproduction in a randomly varying environment. J Theor Biol 12:119-129.

Elberse IAM, JMM van Damme, PH van Tienderen 2003 Plasticity of growth characteristics in wild barley (Hordeum spontaneum) in response to nutrient limitation. J Ecol 91:371-382.

Elberse IAM, TK Vanhala, JHB Turin, P Stam, JMM van Damme, PH van Tienderen In press Quantitative trait loci affecting growth- related traits in wild barley (Hordeum spontaneum) grown under different levels of nutrient supply. Heredity.

Evenari M 1965 Physiology of seed dormancy: after-ripening and germination. Proc Int Seed Test Assoc 30:49-71.

Evenari M, L Shanan, N Tadmor 1971 The Negev, the challenge of a desert. Harvard University Press, Cambridge, Mass.

Falconer DS, TFC Mackay 1996 Introduction to quantitative genetics. Longman Scientific \& Technical, Harlow.

Friedman J, Z Stein, E Rushkin 1981 Drought tolerance of germinating seeds and young seedlings of Anastatica bierochuntica L. Oecologia 51:400-403.

Giles BE 1990 The effects of variation in seed size on growth and reproduction in the wild barley Hordeum vulgare ssp. spontaneum. Heredity 64:239-250.

Gutterman Y 1993 Seed germination in desert plants: adaptations of desert organisms. Springer, Berlin.

Gutterman Y, S Gozlan 1998 Amounts of winter or summer rain triggering germination and "the point of no return" of seedling desiccation tolerance of some Hordeum spontaneum local ecotypes in Israel. Plant Soil 204:223-234.

Harlan JR, D Zohary 1966 Distribution of wild wheats and barley. Science 153:1074-1080.

Harper JL, PH Lovell, KG Moore 1970 The shapes and sizes of seeds. Annu Rev Ecol Syst 1:327-351.

Houssard C, J Escarre 1991 The effects of seed weight on growth and competitive ability of Rumex acetosella from two successional old-fields. Oecologia 86:236-242.

Jaffe S 1988 Climate of Israel. Pages 79-94 in Y Yom-Tov, E Tchernov, eds. The zoogeography of Israel. Junk, Dordrecht.

Lander ES, D Botstein 1989 Mapping Mendelian factors underlying quantitative traits using RFLP linkage maps. Genetics 121:185-199. 
Legendre P, L Legendre 1998 Numerical ecology. 2d English ed. Elsevier Science, Amsterdam.

Lloret F, C Casanovas, J Peñuelas 1999 Seedling survival of Mediterranean shrubland species in relation to root : shoot ratio, seed size and water and nitrogen use. Funct Ecol 13:210-216.

Marañón T, PJ Grubb 1993 Physiological basis and ecological significance of the seed size and relative growth rate relationship in Mediterranean annuals. Funct Ecol 7:591-599.

Nevo E 1992 Origin, evolution, population genetics and resources for breeding of wild barley, Hordeum spontaneum, in the Fertile Crescent. Pages 19-43 in PR Shewry, ed. Barley: genetics, biochemistry, molecular biology and biotechnology. CAB International, Wallingford.

Nevo E, A Beiles, Y Gutterman, N Storch, D Kaplan 1984 Genetic resources of wild cereals in Israel and vicinity. II. Phenotypic variation within and between populations of wild barley, Hordeum spontaneum. Euphytica 33:737-756.

Nevo E, A Beiles, D Zohary 1986 Genetic resources of wild barley in the Near East: structure, evolution and application in breeding. Biol J Linn Soc 27:355-380.

Nevo E, D Zohary, AHD Brown, M Haber 1979 Genetic diversity and environmental associations of wild barley, Hordeum spontaneum, in Israel. Evolution 33:815-833.

Remington DL, MD Purugganan 2003 Candidate genes, quantitative trait loci, and functional trait evolution in plants. Int J Plant Sci 164(suppl):S7-S20.

SAS Institute 1997 SAS/STAT software: changes and enhancements through release 6.12. SAS Institute, Cary, N.C.

Schimpf DJ 1977 Seed weight of Amaranthus retroflexus in relation to moisture and length of growing season. Ecology 58:450-453.

Schütz W, P Milberg, BB Lamont 2002 Germination requirements and seedling responses to water availability and soil type in four eucalypt species. Acta Oecol 23:23-30.

Silvertown J 1989 The paradox of seed size and adaptation. Trends Ecol Evol 4:24-26.

Smith CC, SD Fretwell 1974 The optimal balance between size and number of offspring. Am Nat 108:499-506.

Snow L, T Brody 1984 Genetic variation of Hordeum spontaneum in Israel: eco-geographic races, detected by trait measurements. Plant Syst Evol 145:15-28.

Stanton ML 1984 Seed variation in wild radish: effect of seed size on components of seedling and adult fitness. Ecology 65:1105-1112.
Thompson K, SR Band, JG Hodgson 1993 Seed size and shape predict persistence in the soil. Funct Ecol 7:236-241.

van Ooijen JW 1992 Accuracy of mapping quantitative trait loci in autogamous species. Theor Appl Genet 84:803-811.

van Ooijen JW, C Maliepaard 1996 MapQTL. Version 4.0: software for the calculation of QTL positions on genetic maps. CPRO-DLO, Wageningen.

Verhoeven KJF, A Biere, E Nevo, JMM van Damme 2004a Differential selection of growth rate-related traits in wild barley, Hordeum spontaneum, in contrasting greenhouse nutrient environments. J Evol Biol 17:184-196.

Verhoeven KJF, TK Vanhala, A Biere, E Nevo, JMM van Damme $2004 b$ The genetic basis of adaptive population differentiation: a QTL-analysis of fitness traits in two wild barley populations from contrasting habitats. Evolution 58: 270-283.

Volis S, S Mendlinger, D Ward 2002a Adaptive traits of wild barley plants from Mediterranean and desert origin. Oecologia 133: 131-138.

$2002 b$ Differentiation in populations of Hordeum spontaneum along a gradient of environmental productivity and predictability: life history and local adaptation. Biol J Linn Soc 77: 479-490.

- 2002c Differentiation in populations of Hordeum spontaneum Koch along a gradient of environmental productivity and predictability: plasticity in response to water and nutrient stress. Biol J Linn Soc 75:301-312.

Westoby M, M Leishman, J Lord 1996 Comparative ecology of seed size and dispersal. Philos Trans R Soc Lond B Biol Sci 351: 1309-1318.

Wulff RD 1986 Seed size variation in Desmodium paniculatum. II. Effects on seedling growth and physiological performance. J Ecol 74:99-114.

Zhang F, Y Gutterman, T Krugman, T Fahima, E Nevo 2002 Differences in primary dormancy and seedling revival ability for some Hordeum spontaneum genotypes of Israel. Isr J Plant Sci 50: 271-276.

Zohary D 1969 The progenitors of wheat and barley in relation to domestication and agricultural dispersal in the Old World. Pages 47-66 in PJ Ucko, GW Dimbleby, eds. The domestication and exploitation of plants and animals. Duckworth, London. 